cone Structure," mentioned in March Number of Geol. Mag., offered a short explanation, that seems satisfactory to myself, and others, that have seen my specimens,-regarding the radiated and inverted structure of the cones, sometimes seen in nodular masses; this rarliation, as stated in paper, pp. 26,27 , being due to secondary causes that had acted on the cone stratum after the cone structure itself had been developed.

I point out in my paper, in the first place, that the cones, in any continuous level stratum, were evidently formed, through the upward escape of gases from below, whilst the stratum itself was being deposited the cones, invariably having their apices directed downwards to the lower part of the bed. In those cone strata where there has been an after-tendency in the sediments to aggregate into nodular masses, these nodules, in their contraction from larger into smaller dimensions, during their solidification, often show clear evilence of the gradual pulling of the cones, from their former erect position, all over the surface of the nodules; they radiating, outwards, from the centre to the circumference, there also being evidence of much crushing and distortion of the cone structure all along their outer edges. I further point out that "where the contraction would be greatest, as in the more argillaceous nodnles, there may have been a bending, and in some instances a complete inversion of the cones around the edges of the nodules."

Since my paper was printed, in 1886, I have obtained many other illustrative specimens from our Scottish coal-field. These clearly show that the radiation and inversion of the cones, in nodular masses, was due to after secondary causes, the cone structure being first, the formation of the nodules being second, and the amount of radiation, and inversion of the cones, affords a measure of evidence as to the amount of contraction that has taken place amongst these nodules previous to complete solidification.

Hunterian Museum, University, Glasgow. May $9 t h, 1892$.

JoHn Youna.

\title{
DISSIPATION OF ENERGY AS A GEOLOGICAL FACTOR.
}

Sir,-Many readers of the Geological Magazine will, perhaps, be glad to have their attention drawn to to the following passage, which concludes an article by Iord Kelvin (P.R.S.), on "Dissipation of Energy," in the "Fortnightly Review" for March, 1892 :

"'The whole store of energy now in the sun, whether of actual heat, corresponding to the sun's high temperature, or of potential energy (as of a not run-down weight of clockwork)-potential energy of gravitation depending on the extent of future shrinkage which the sun is destined to experience, is essentially finite; and there is much less of it now than there was three hundred thousand years ago. Similar considerations of action on a vastly smaller scale are, of course, applicable to terrestrial plutonic energy, and thoroughly dispose of the terrestrial 'perpetual motion,' by which Lyell and other followers of Hutton, on as sound principles as those of the humblest mechanical perpetual-motionist, tried to find that 
the earth can go on for ever as it is. illuminated by the sun from infinity of time past to infinity of time future, always a habitation for race after race of plants and animals, built on the ruins of the habitations of preceding races of plants and animals. The doctrine of the 'Dissipation of Energy' forces upon us the conclusion that within a finite period of time past the earth must have been, and within a fivite period of time to come must again be, unfit for the habitation of man as at present constituted, unless operations have been, and are to be, performed, which are impossible under the laws governing the known operations going on at present in the material world."

There can be no necessity for pointing out the importance of this dictum from the pen of Lord Kelvin; it supports my own contention in the Geological Magazine of July and October, 1891 (pp. 300 and 479-80). I will not intrude upon your space by reiterating what I have already put into print, but I trust you will, with your usual courtesy, allow me to refer the reader to such passages as are to be found in my little work. ${ }^{1}$ In the light of what I have quoted above from Lord Kelvin it can scarcely be said that I spoke too strongly in animadversion on the Huttonian School, in the concluding paragraph of my "Note on the Airolo Schists Controversy" in 1890 (See Grol. Mag. Dec. III. Vol. VII. p. 259).

The concluding paragraph of Sir A. Geikie's Presidential Address to the Geological Society for 1892 shows how opinion is veering at the present moment; and during the present session two papers of importance have appeared, one by Professor Bonney and Gen. MacMahon, another by Messrs. Dakins and Teall, in which attempts have been made to work out the history of the structural phenomena observable in igneous masses of particular areas on principles applicable to an universal magma, at a period of the Earth's history when the energy since dissipated by radiation into space was concentrated in the lithosphere. A great deal of what the writers referred to have now put forward was seen more than forty years ago by that sagacious geologist, the late Prof. John Phillips, F.R.S., as applicable to the crystalline rocks of the Malvern range (see Mem. Geol. Survey, vol. ii. part 1), which he saw, with an insight not befogged by the later mists of "regional metamorphism," to be in the main a truly igneous series. On the Malvern Crystallines I hope, after ten weeks' hammering at them, to have more to say anon.

A. Irving.

Wellington College, Berks, 11th May, 1892.

EARTHQUAKE SOUNDS.

Sir,-There are one or two points in Mr. C. Davison's paper on earth-quake-sounds I should like to draw attention to.

In most Italian tectonic earthquakes, the sound phenomena precede the mechanical disturbances, though the former overlap the latter the nearer the epicentrum is approached. 'This means that

1 "Metamorphism of Rocks" (London, 1889), see pp. 18, 19, 22, 23, 70, 71, 94, 95 , and 96 . 